\title{
A QUANTITATIVE MODEL FOR DESCRIBING SNOWLINES IN THE CENTRAL ANDES MOUNTAINS
}

A.N.Fox'

\section{ABSTRACT}

The modern snowline elevation of the central Andes can be described numerically from available data in terms of regional variations in climate and topography. Multiple regression analysis of modern climatic and snowline data for locations in the Andes between $10^{\circ}$ and $30^{\circ}$ south latitude produces an equation which relates snowline elevation to mean annual temperature, precipitaton, and the elevation of the annual $0^{\circ} \mathrm{C}$ isotherm. The coefficient of correlation $(R=0.83)$ for this model is considered to be significant because most of the remaining error can be attributed to the variability of the reported snowline observations which have not yet been evaluated for errors. An inversion of the model should ultimately allow, for the first time, a quantitative reconstruction of Andean paleoclimates from Pleistocene snowline data. The ultimate goal is to determine the differences between glacial and modern climates, not only for the Andes but for other major mountain belts of the world.

\section{INTRODUCTION}

The evaluation of present and past snowline elevations is important for climatic interpretations because they reflect the net interaction between weather systems and topography. Geomorphic evidence of former valley and cirque glaciers below the modern snowline in the central Andes demonstrates that significant climate change has occurred during the late Quaternary. The term snowline as applied in this paper refers to the lowest limit of permanent snow on mountain slopes averaged

\footnotetext{
${ }^{1}$ Departament of Geological Sciences-Snee Hall, Cornell University, lthaca, New York 14853 USA.
} 
regionally and over many years (i.e., climatic snowline). Snowline elevations and gradients, along with the size and distribution of glaciers, are determined by climate (temperature, precipitation, and wind direction) and topography (mountain elevation and morphology). The investigation of the relationship between this variables is complicated between $23^{\circ}$ and $32^{\circ}$ south latitude in a significant zone of regionally abrupt changes in all of the above factors (Fig. 1). This situation provides a unique opportunity to study the interrelationship of spatially and temporally changing climatic and topographic variables on landscape evolution, and is the primary reason why this portion of the central Andes was selected for investigation. The observed vertical change in snowline elevation through time permits inferences about temporal variations in climate as long as there is a demonstrable relationship between snowline elevation and climatic parameters.

\section{THE ANDEAN SNOWLINE MODEL}

\section{Data compilation analysis}

I have compiled available data on snowline positions and climatic parameters from numerous published and unpublished sources, including values of surface temperature, precipitation and evaporation. Although the database contains records for the entire Andes, this study concentrates on the central Andes between $10^{\circ}$ and $30^{\circ}$ south latitude. The locations of the 718 stations with snowline and/or climate data used in this study are shown in Figure 2.

To determine whether or not a general correspondence exists between the regional change in climatic parameters and snowline gradients, a series of topo-climatic profiles, each 1,000 km long and $100 \mathrm{~km}$ wide were constructed at $1^{\circ}$ latitude intervals across the Andes, although only 3 representative profiles are included here (Figs. 3-5). The topograpic profiles represent the averaged topography for a 100 $\mathrm{km}$ wide swath along the profile trend, and are based upon a $5 \times 5 \mathrm{~km}$ grid. Although the elevation and distribution of the highest peaks control climatic and snowline patterns on a local scale, averaged topography was selected for clarification of regional trends.

Temperature is very sensitive to changes in surface elevation (Fig. 6) and is controlled by the regional temperature lapse rate. The temperature curves in Figures 3-5 illustrate this relationship, with higher portions of the averaged topography having lower mean temperatures.

Topography also controls the zones of highest precipitation by acting as a barrier as well as a lifting mechanism for moisture-bearing winds. Within the latitudes of the study area, these winds are predominantly from an easterly direction, so that the lifting condensation level is reached by moist air rising over the Andes producing a classic rain shadow effect to the west. As a result, annual mean precipitation is 


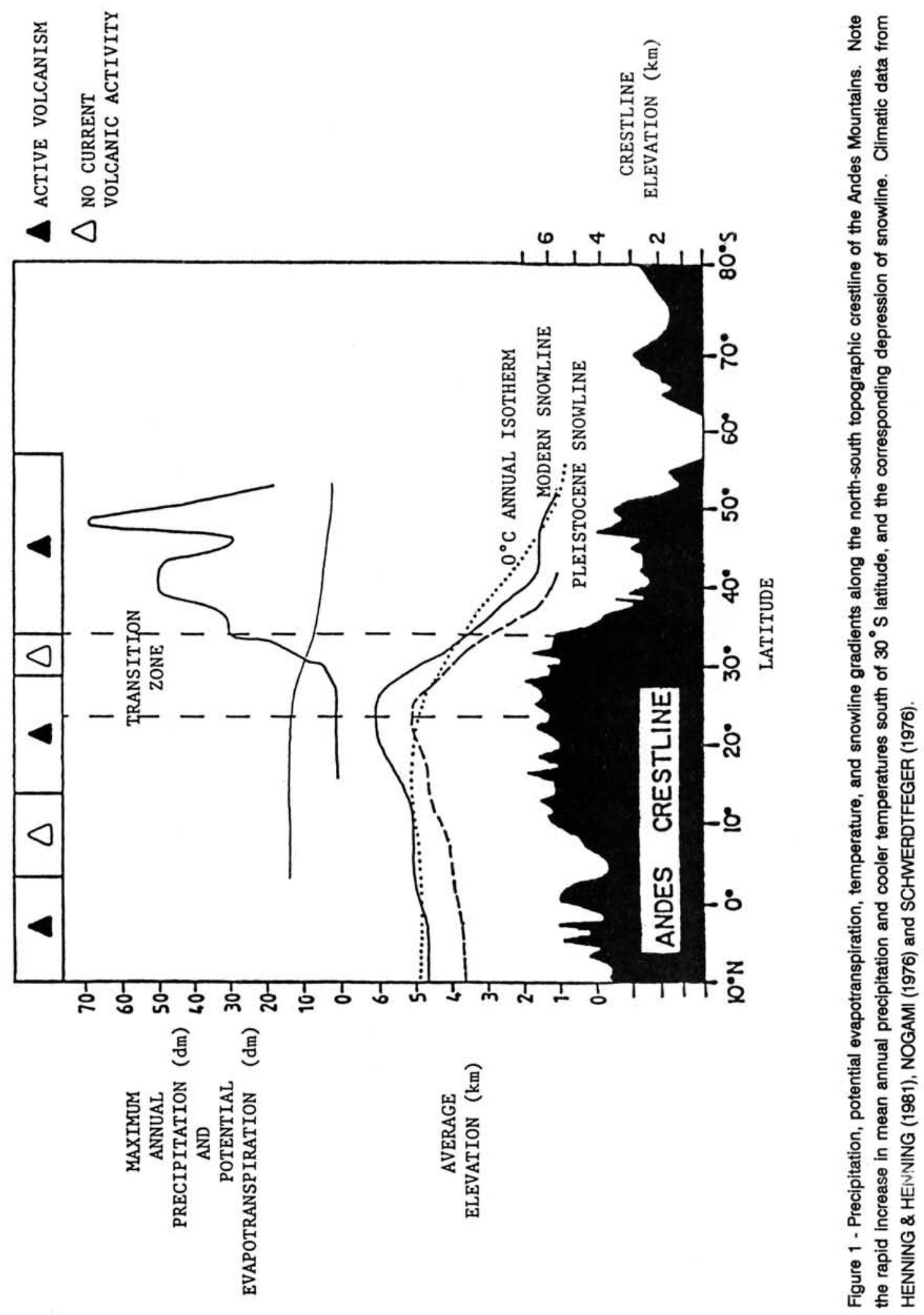




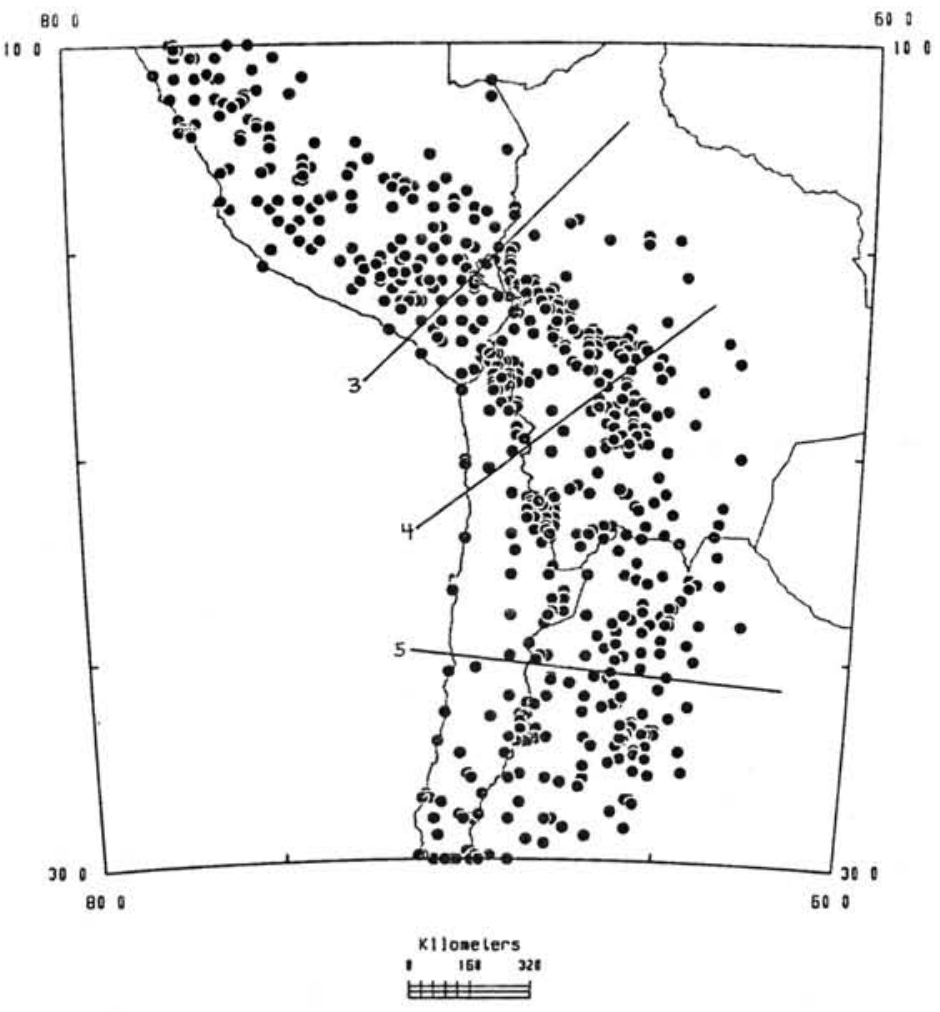

Figure 2 - Location of 718 central Andean climate and snowline observation stations used in this study. Coordinates are in degrees south latitude and west longitude. Axes of the profiles in Figures 3-5 (north-south) are also shown.

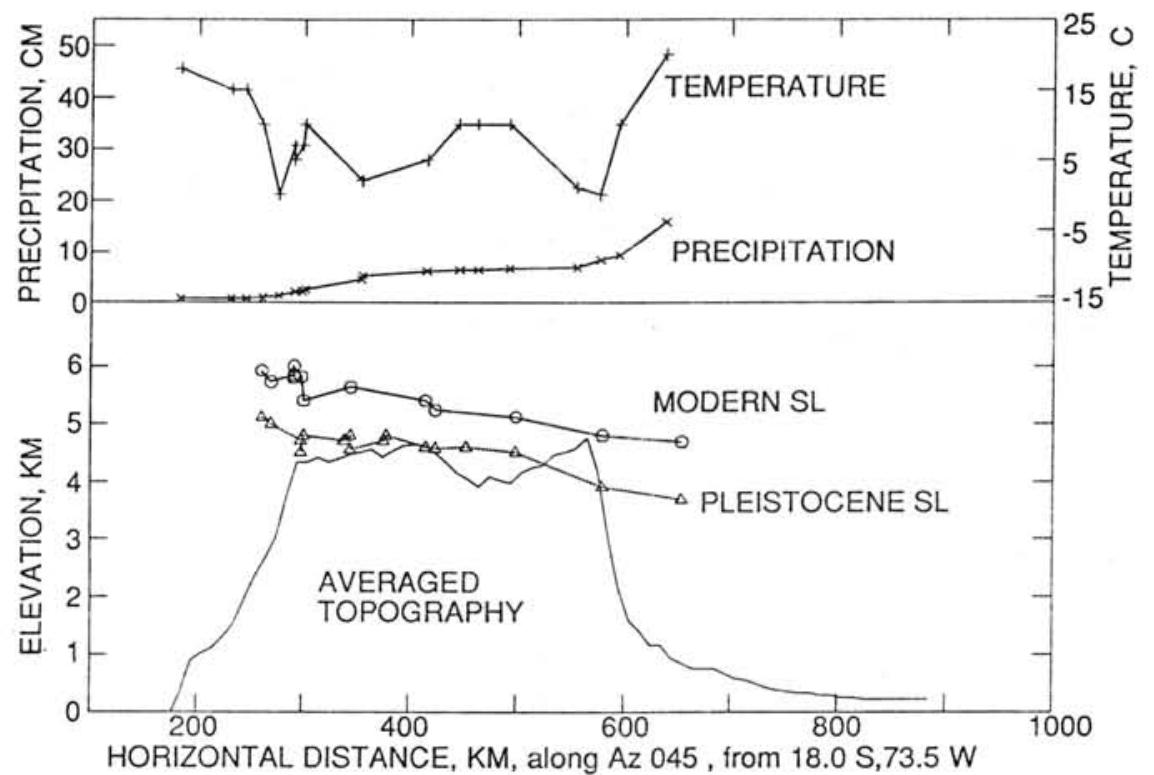

Figure 3 - Topo-climatic profile across the Andes. Profile width is $100 \mathrm{~km}$, and length is in kilometers from $18^{\circ} \mathrm{S}, 73.5^{\circ} \mathrm{W}$ along an azimuth $45^{\circ}$ east of geographic north. 


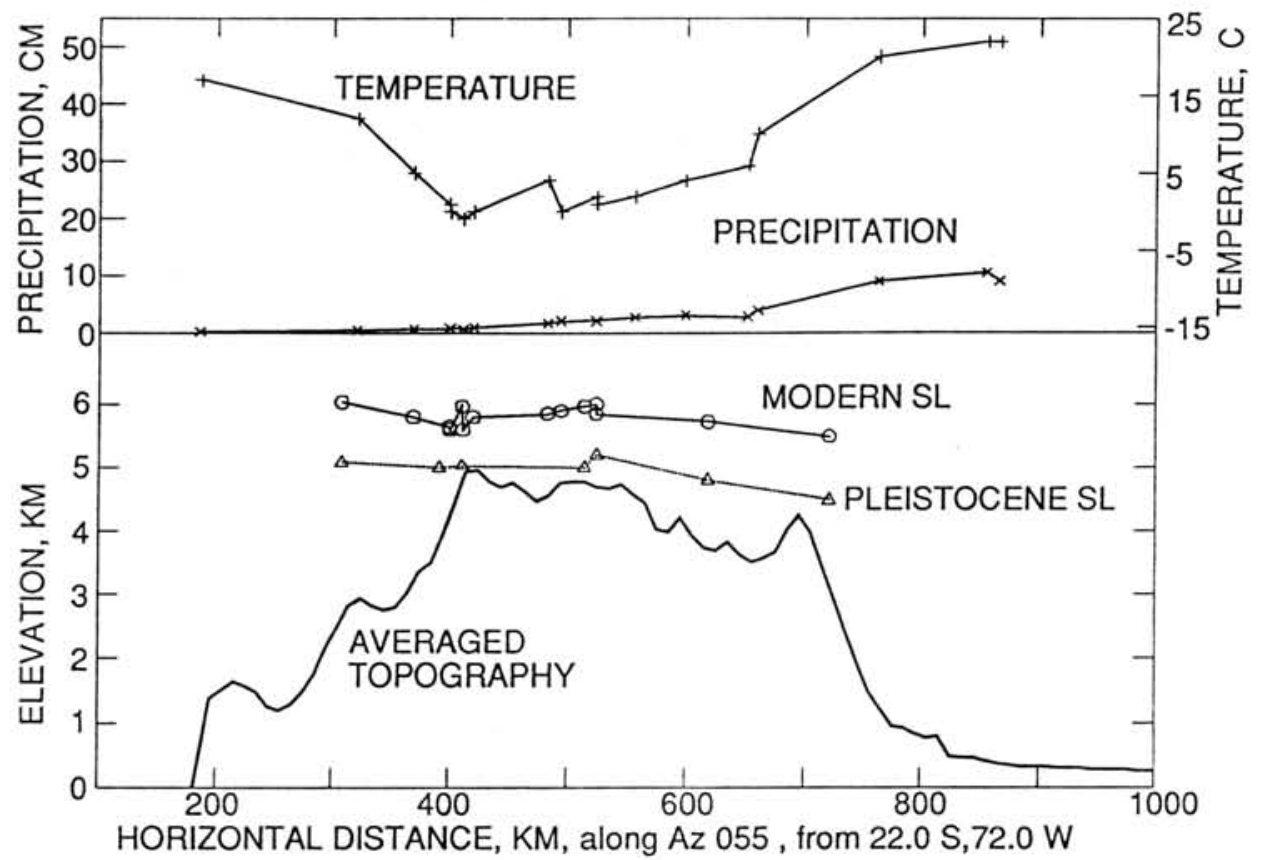

Figure 4 - Topo-climatic profile across the Andes. Profile width $100 \mathrm{~km}$, and length is in kilometers from $22^{\circ} \mathrm{S}, 72^{\circ} \mathrm{W}$ along an azimuth $55^{\circ}$ east of geographic north.

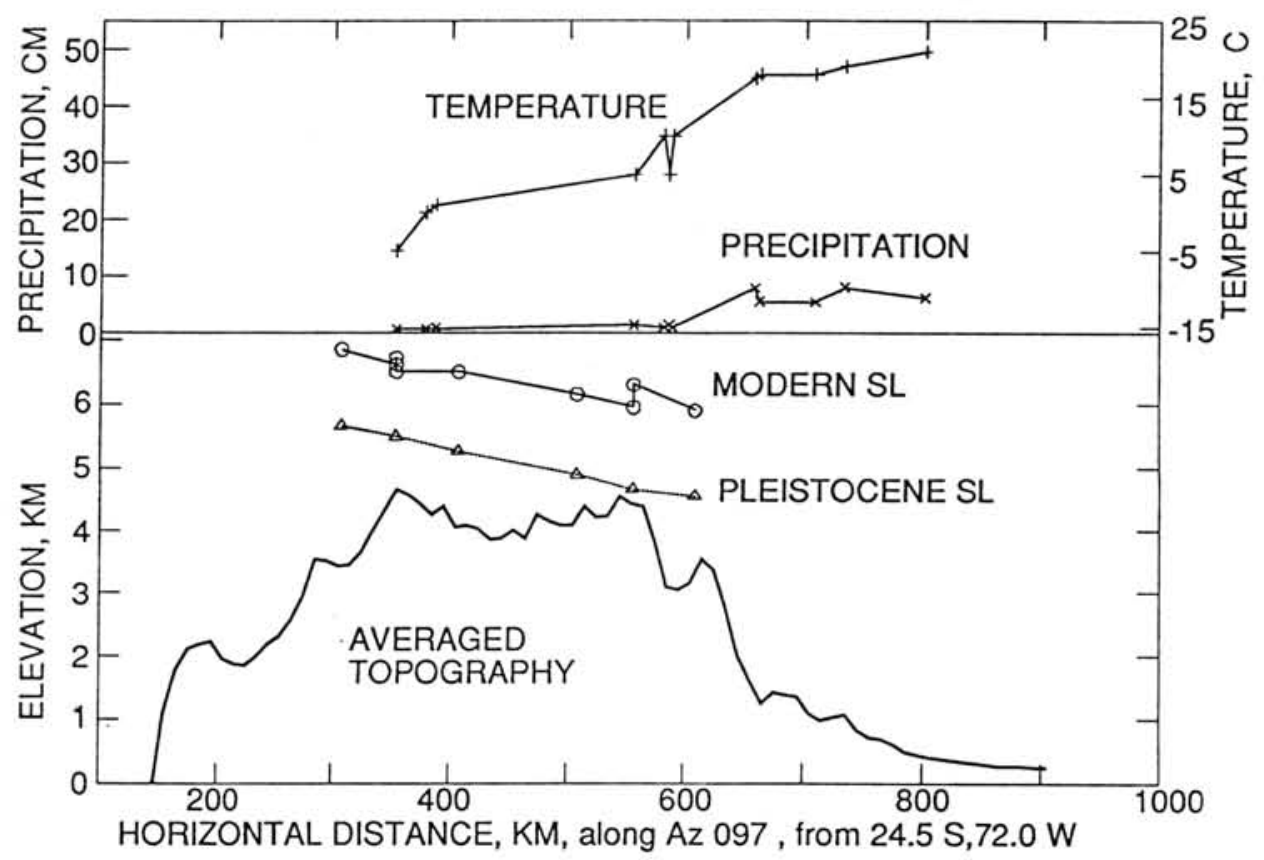

Figure 5 - Topo-climatic profile across the Andes. Profile width is $100 \mathrm{~km}$, and length is in kilometers from $24.5^{\circ} \mathrm{S}, 72^{\circ} \mathrm{W}$ along an azimuth $97^{\circ}$ east of geographic north. 
greater on the eastern side of the Andean Cordillera in the study area (Figs. 3-5). A comparison of scatter plots in Figures 6 and 7 show that precipitation is less sensitive than temperature to variations in elevation. The combined temperature/precipitation effect on snowline position is interesting, however, because higher peaks tend to have higher modern snowlines (Fig. 8). Most snowlines are within $1 \mathrm{~km}$ below nearby mountain peaks, regardless of snowline elevation or climatic regime. This relationship suggests a dynamic feedback mechanism between climate and topography.

In general, snowline gradients are consistent with climatic trends. Snowlines are lower to the east where annual precipitation is greater. An apparent contradiction exists between the eastward drop in snowline elevation and a general rise in temperature to the east, where surfaces are warmer because they are lower (Figs. 3-5). The logical explanation is that higher precipitation effectively maintains lower snowline positions despite slightly higher surface temperatures.

\section{MODEL DEVELOPMENT}

Annual mean temperature and precipitation are taken to be the primary climatic factors controlling regional snowline elevation, and are the most reliable and spatially comprehensive measurements available in the central Andes. Secondary controlling factors, such as evaporation, are also important but cannot be adequately quantified because of lack of data, and probably influence the regional snowline elevation only minimally. In order to determine the empirical relationship between the modern swowline elevation and the primary climatic parameters, the annual mean temperature and precipitation were plotted separately against the corresponding snowline elevation.

Figure 9 illustrates the simple linear relationship between mean annual temperature and modern snowline elevation in the central Andes. Lower snowlines generally correspond with higher surface temperatures. Again, this apparent contradiction is explained by normal temperature lapse rates in the lower troposphere, where lower surfaces have higher temperatures.

Isotherms are often used to quantify and display the spatial variation in regional temperature. Because an annual mean temperature near or below freezing is required to maintain perennial snow, and because the freezing level varies by over $6 \mathrm{~km}$ in elevation throughout the entire Andes, the incorporation of the annual $0^{\circ} \mathrm{C}$ isotherm elevation parameter into the model is justified in order to provide a reference level from which to calculate the snowline elevation. The relationship between the annual $0^{\circ} \mathrm{C}$ isotherm and modern snowline elevation is shown in Figure 10. Notice that in this portion of the central Andes $\left(10^{\circ}\right.$ to $30^{\circ}$ south), there is little variation in the elevation of the isotherm. This situation imip ies that the annual $0^{\circ} \mathrm{C}$ isotherm elevation does not directly account for the variation in modern snowline elevations in the central Andes. The isotherm elevation variable has, however, been incorporated into the present 


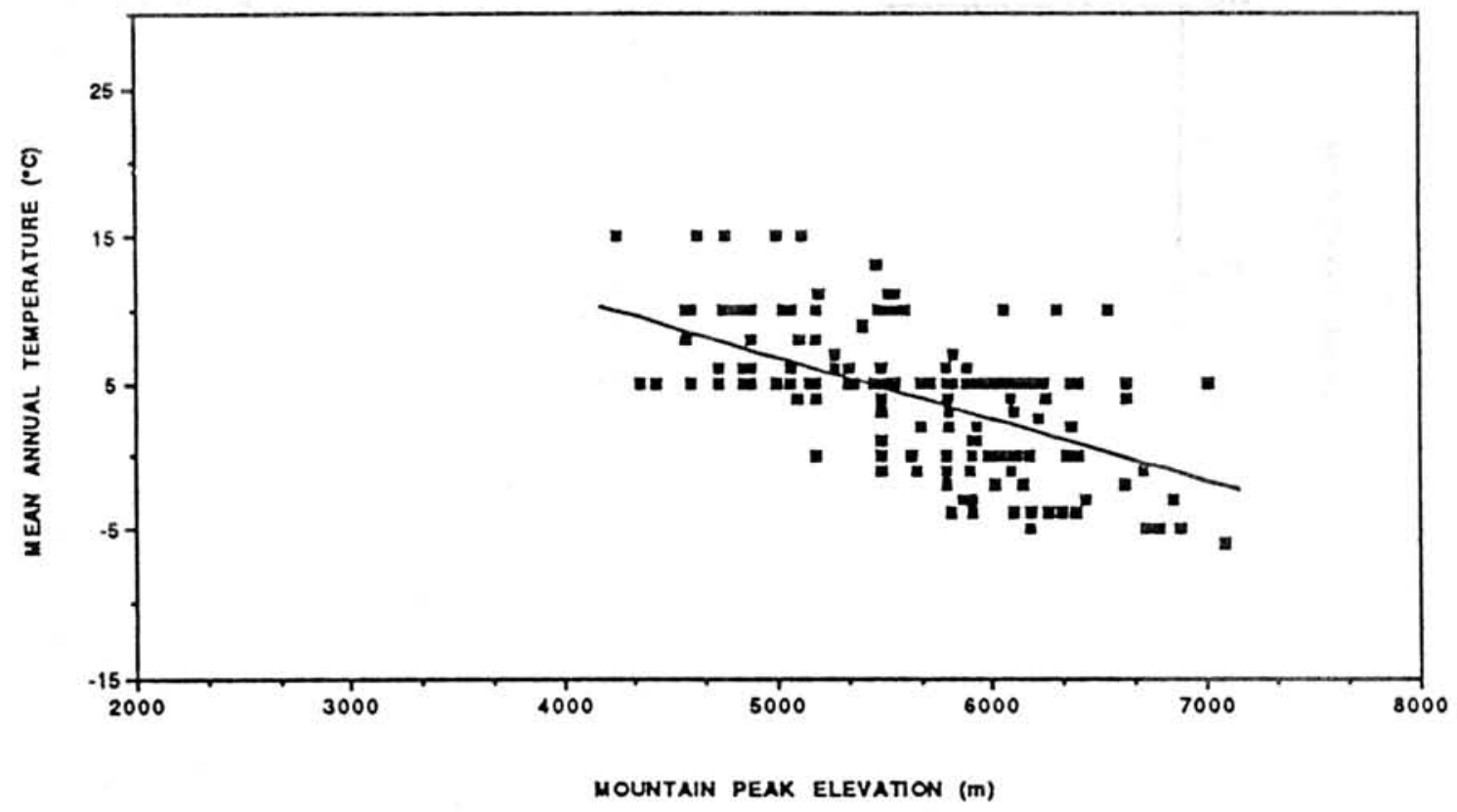

Figure 6 - Comparison of mountain peak elevation and mean annual temperature in the central Andes $\left(10-30^{\circ} \mathrm{S}\right.$ latitude).

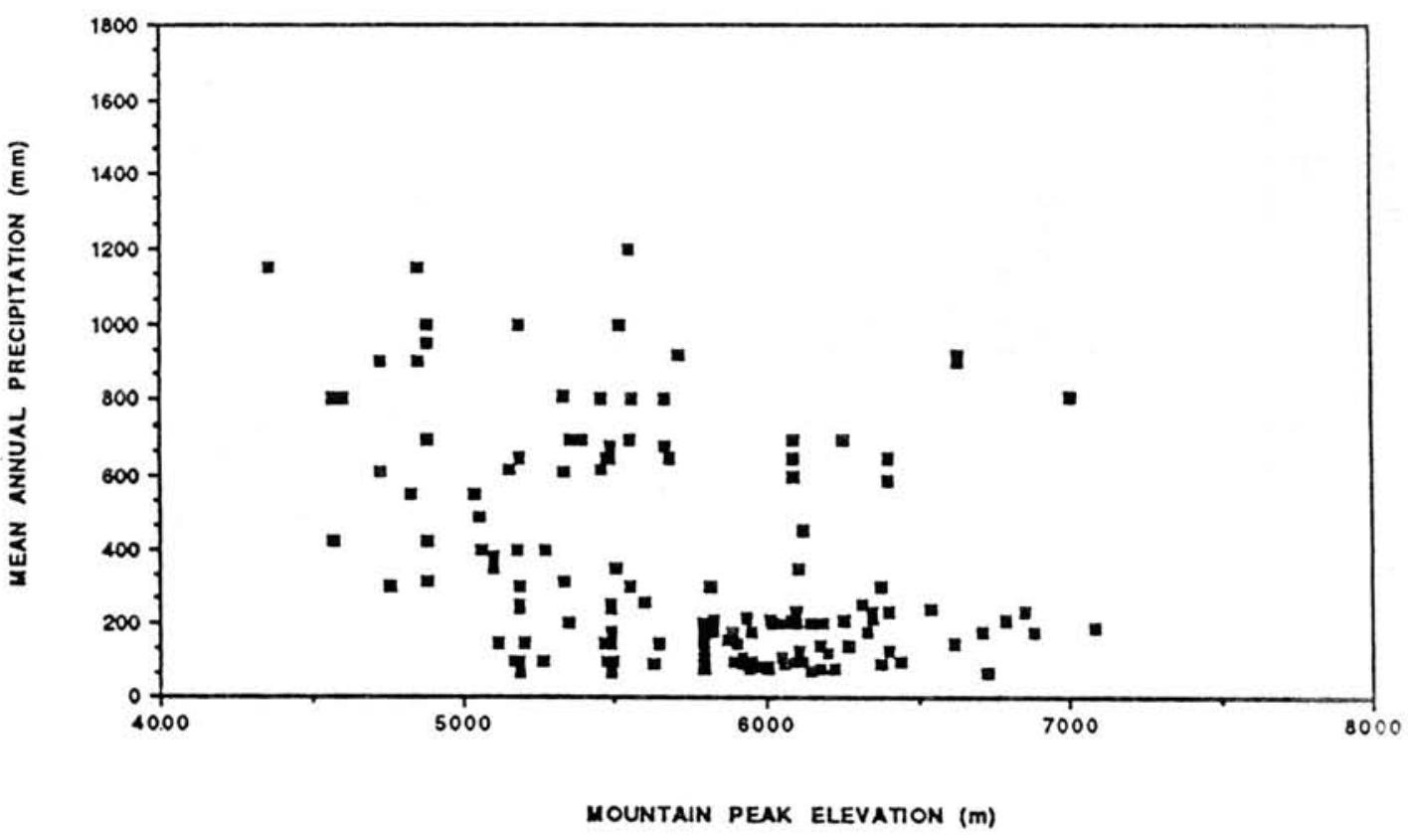

Figure 7 - Comparision of mountain peak elevation and mean annual precipitation in the central Andes $\left(10-30^{\circ} \mathrm{S}\right.$ latitude). 


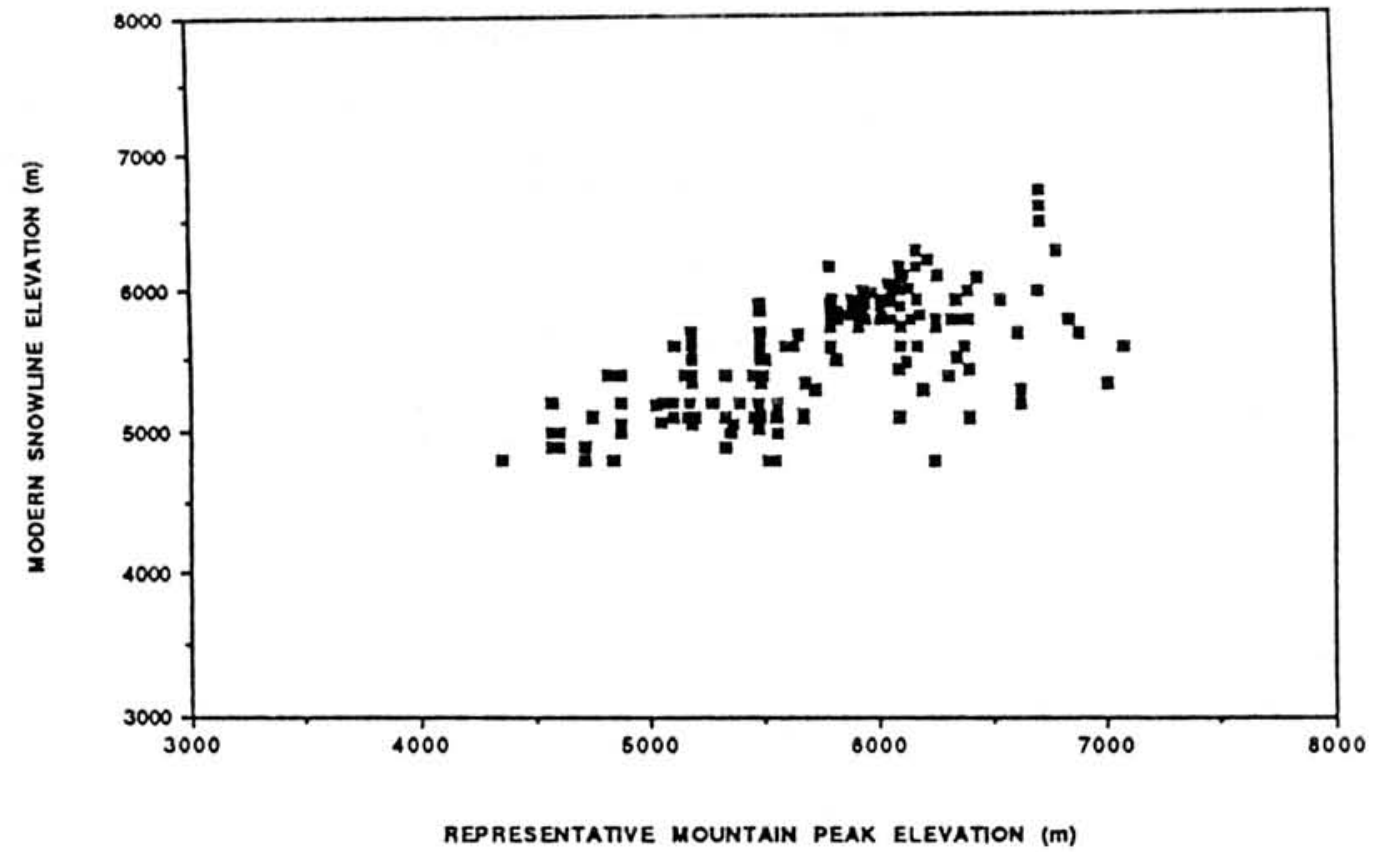

Figure 8 - Comparison of mountain peak elevation and modern snowlime elevation in the central Andes (10-30 ${ }^{\circ} \mathrm{S} \mathrm{latitude).}$

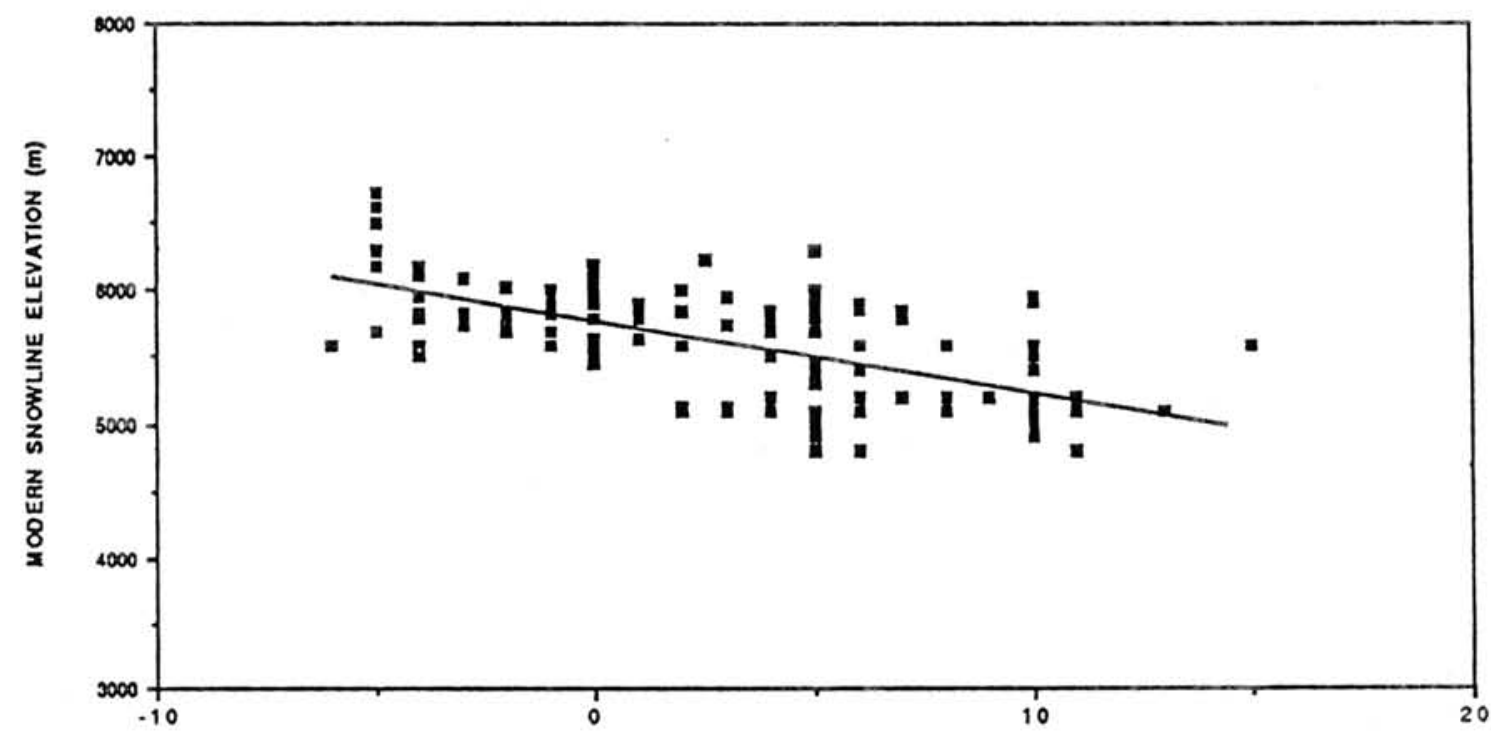

MEAN ANNUAL TEMPERATURE ('C)

Figure 9 - Comparison of mean annual temperature and modern snowline elevation in the central Andes (10-30 $\mathrm{S}$ latitude). 
model as a mathematical reference, and for intended future modeling north and south of the central Andes where regional variations in the annual $0^{\circ} \mathrm{C}$ isotherm elevation are significant.

Modern snowline altitude was also plotted against mean annual precipitation, and a second-order polynomial regression was determined to be the "best fit" (Fig. 11). In general, a large increase in precipitation is required to lower snowline by only a few hundred meters. As can be seen in Figures 3-5, modern snowlines are as much as $2 \mathrm{~km}$ above the averaged topography in the central Andes depending upon mean annual precipitation. For example, the profiles in Figures 3-5 show that from north to south, and from west to east, an increase in precipitation produces a corresponding drop in modern snowline elevation in relation to the avaraged topography.

It is acknowledged that evaporation modifies the importance of annual precipitation in determining snowline elevation, but it appers that an increase in the rate of evaporation, physically linked to a corresponding rise in temperature, is offset by a similar increase in precipitation. As mentioned above, measured values for surface evaporation in the central Andes are sparse, and have not been incorporated into the model. Available evaporation data are based empirically on temperature data, and indicate a strong correlation between measured precipitation and calculated effective precipitation (precipitation minus evaporation). Despite the strong correlation illustrated in Figure 12, annual precipitation was selected as the more appropriate parameter for modeling bacause of the higher degree of confidence in measured rather than calculated values.

After the relationships between the mean annual surface temperature, precipitation, and $0^{\circ} \mathrm{C}$ isotherm elevation were determined separately, a multiple regression analysis of these variables taken together against modern snowline elevation was the final step in constructing the snowline model. The resulting equation calculated using the StatWorks ${ }^{T M} 1.1$ software packge for the Apple Macintosh is:

\section{MSL ELEV $=0.001(\text { PRECIP })^{2}-2($ PRECIP $)-32($ TEMP $)+0.2\left(0^{\circ} \mathrm{C}\right.$ ELEV $)+5379$}

where MSL ELEV is the modern snowline elevation in meters, PRECIP is the mean annual precipitation in millimeters, TEMP is the mean annual temperature in ${ }^{\circ} \mathrm{C}$, and $0^{\circ} \mathrm{C}$ ELEV is the annual $0^{\circ} \mathrm{C}$ isotherm elevation in meters. Observed modern snowline elevations were then plotted against snowline elevations calculated from the above equation in order to determine the integrity (i.e., $R=0.83$ ) of the model (Fig. 13).

\section{CONCLUSIONS AND IMPLICATIONS}

Snowlines in the central Andes can be modeled numerically in terms of an empirical equation relating snowline elevation to surface mean annual temperature, precipitation, and the $0^{\circ} \mathrm{C}$ 


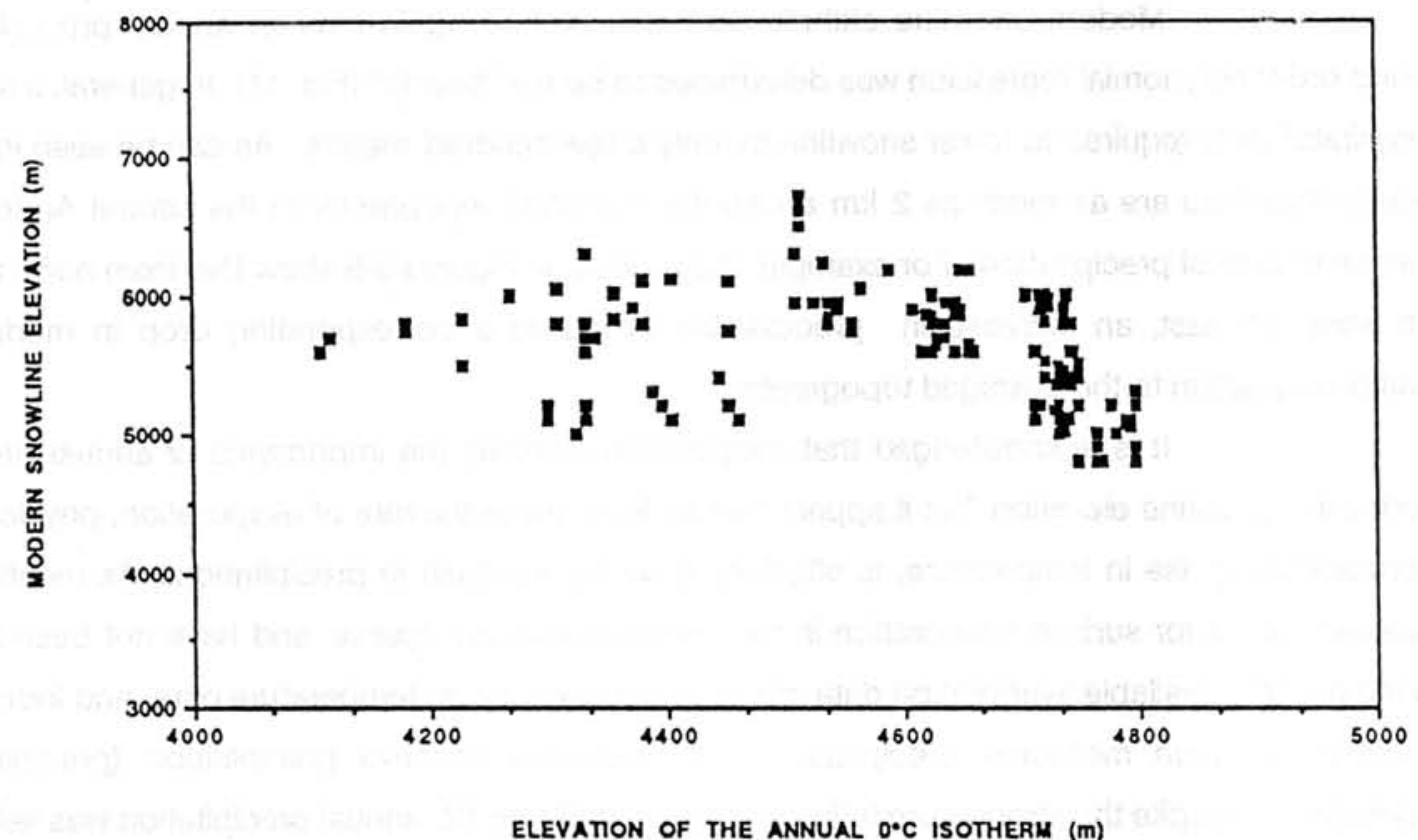

Figure 10 - Comparison of the annual $0^{\circ} \mathrm{C}$ isotherm and modern snowline elevation in the central Andes $\left(10-30^{\circ} \mathrm{S}\right.$ latitude).

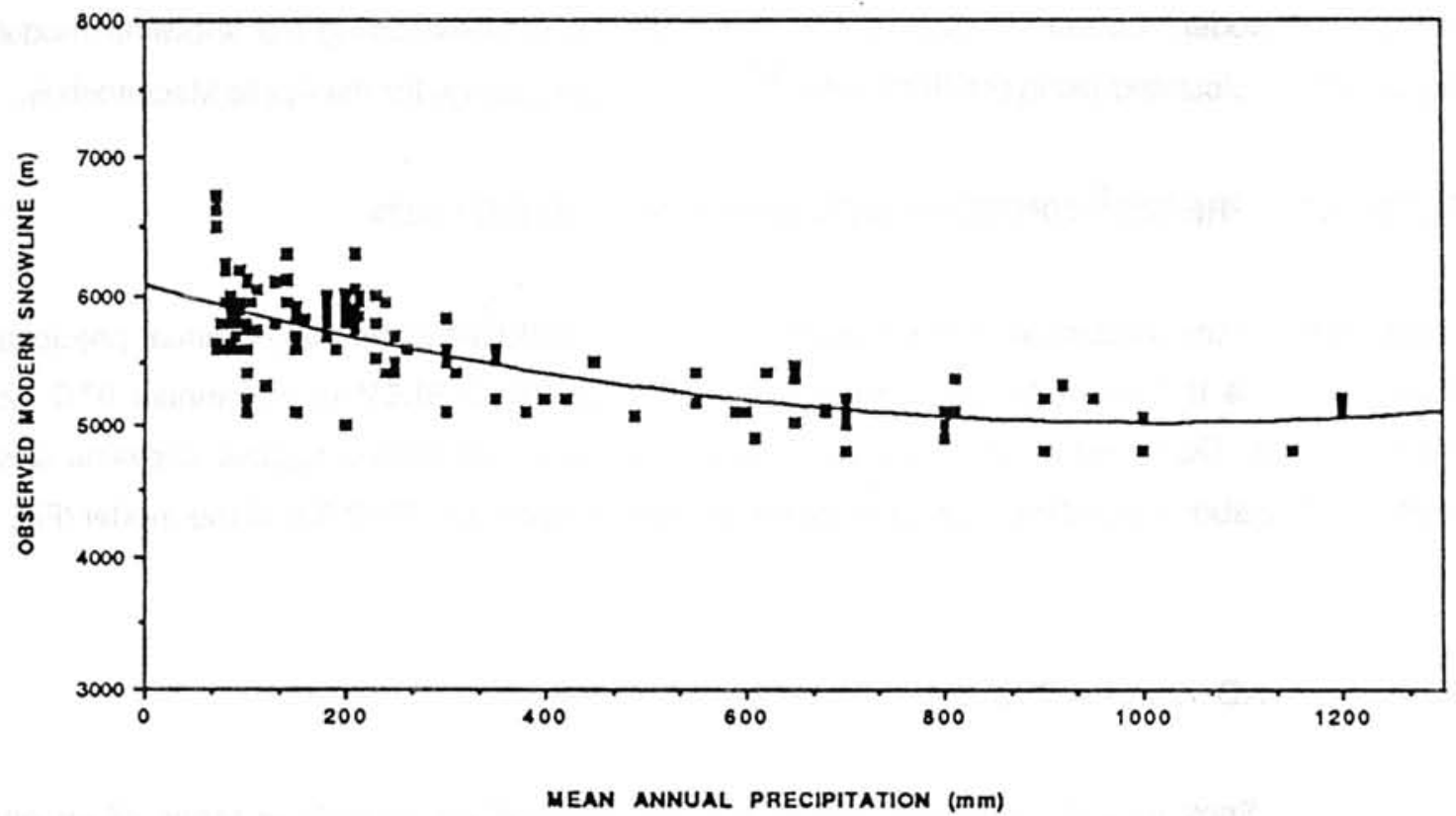

Figure 11 - Comparison of mean annual precipitation and modern snowline elevation in the central Andes (10-30 ${ }^{\circ} \mathrm{S} \mathrm{latitude).}$ 


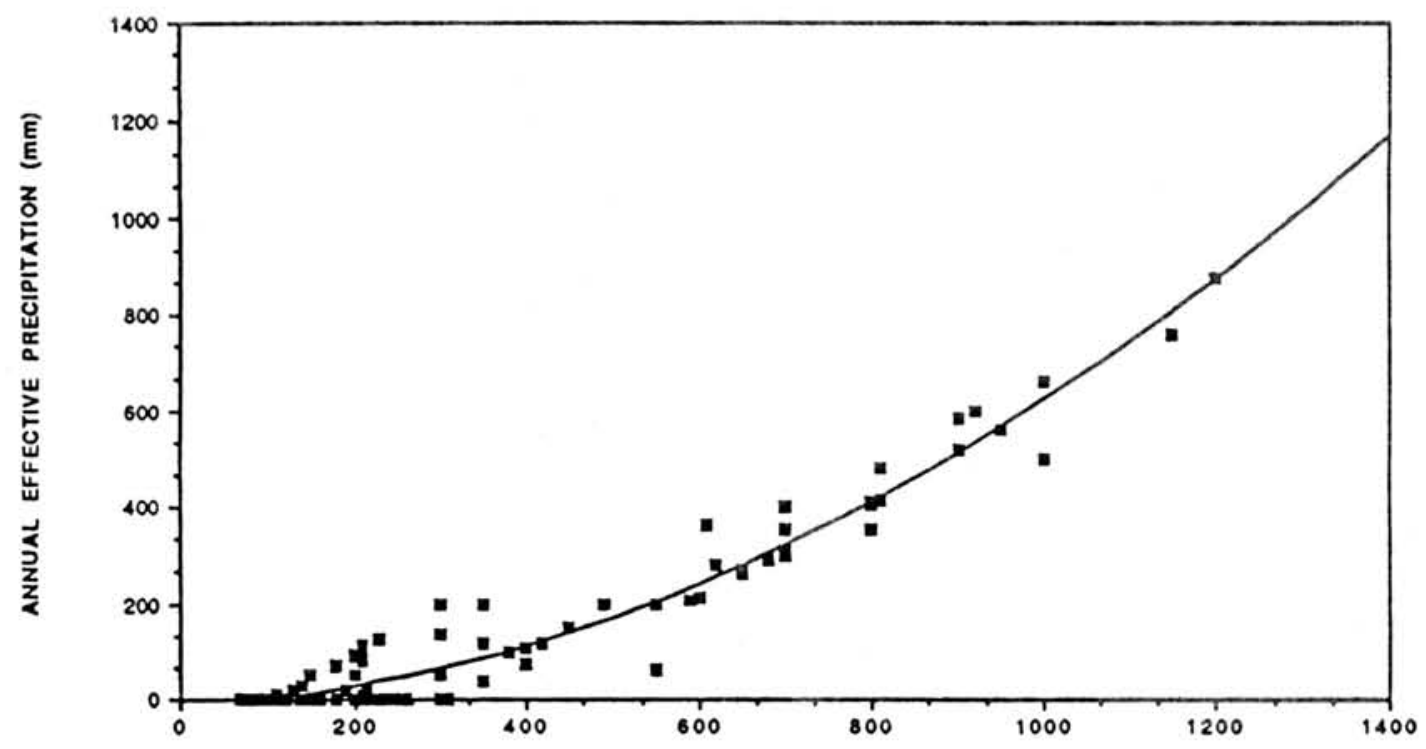

MEAN ANNUAL PREcipitation $(\mathrm{mm})$

Figure 12 - Comparison of mean annual precipitation and effective annual precipitation (precipitation - evaporation) in the central Andes (10-30*S latitude). The coefficient of correlation is 0.98 .

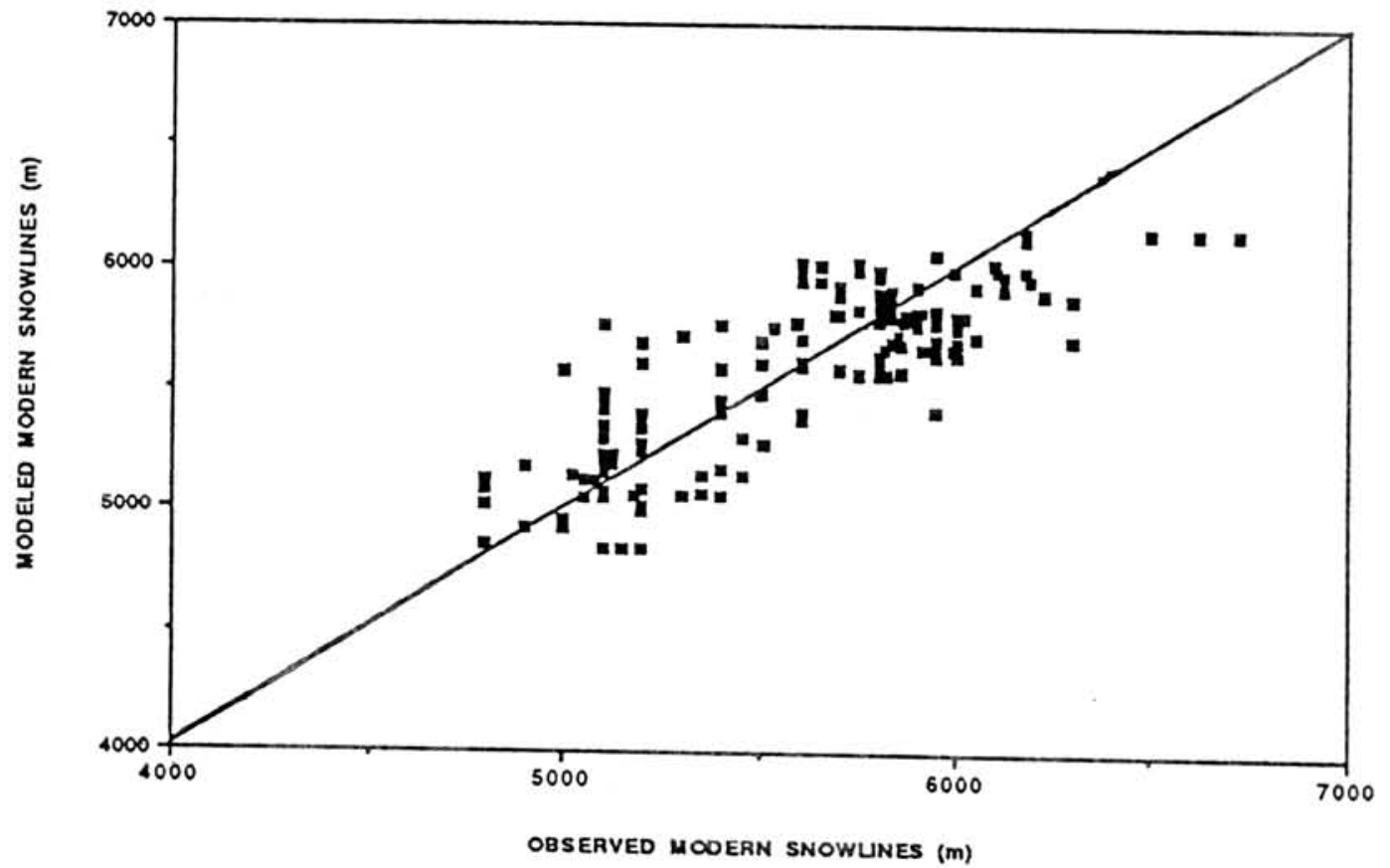
Figure 13 - Comparison of observed and modeled modern snowline elevations in the central Andes (10-30\#S latitude). The
coefficient of correlation is 0.83 . 
isotherm elevation. The coefficient of correlation for this model $(R=0.83)$ is considered to be significant because discrepancies between snowline elevations reported by different authors at different times are assumed to be the source of most of the uncertainty in the model. All reported values for snowline, not yet evaluated for error, were included in the dataset used to construct this model. Analysis of available remotely sensed imagery and evaluation of the criteria used to define snowline position by the various authors are required before select observations can be justifiably removed from the database. Now that an empirical relationship has been developed for paleoclimatic modeling purposes, the task of reevaluating reported snowline observations, and the collection of new ones has become more worthwhile.

The modern latitudinal and longitudinal variation of climatic zones in the Andes allows one to model the results of changing one or more of the factors responsible for glaciation. The model can be applied to proxy climatic data (i.e., cirque floor elevations) of former snowline positions to quantitatively estimate Pleistocene temperature and precipitation values. The late Pleistocene glacial-age snowline elevations are about $800 \mathrm{~m}$ lower, on the average, in altitude and generally parallel to modern ones (Figs. 35 and 14). This suggests a strong similarity in wind and moisture regimes throughout much of the late Quaternary in the central Andes. An inversion of the derived snowline model should ultimately allow a quantitative reconstrucion of Andean paleoclimates from late Pleistocene snowline data. Independently derived estimates for temperature from pollen data, and precipitation from closed basin hydrologic budget modeling will help test the validity of this model. The ultimate goal is to regionally map climatic conditions for the Andes at various times during the late Quaternary. Further work in the Andes, especially in the important climatic transition zone between $23^{\circ}$ and $32^{\circ}$ south latitude where there are only sparse snowline and climatic data, is required.

Extensive summits and plateaus between $21^{\circ}$ and $26^{\circ}$ south latitude are above the altitude of the annual $0^{\circ} \mathrm{C}$ isotherm today, cold enough for permanent snowfields and active rock glaciers but too dry to support major valley glaciers as they did at least twice in the past. The position of the present summer $0^{\circ} \mathrm{C}$ isotherm below the modern and Pleistocene snowlines in this area implies that no decrease in temperature would be required to initiate glaciation, but simply an increase in the amount of pecipitation. This evidence, however, does not preclude a probable lower temperature for the central Andes during Pleistocene glaciations.

Figure 15 shows the areas above late Pleistocene glacial-age snowlines as determined by the author from topographic information integrated with snowline observations compiled by NOGAMI (1976) and by STRECKER (1976). This map illustrates the relative extent of land surfaces subjected one or more times to intense glacial and periglacial modification during the late Quaternary, and serves as a useful guide for selecting sites for future work designed to further increase our knowledge of late Quaternary climates in the Andean Cordillera. 


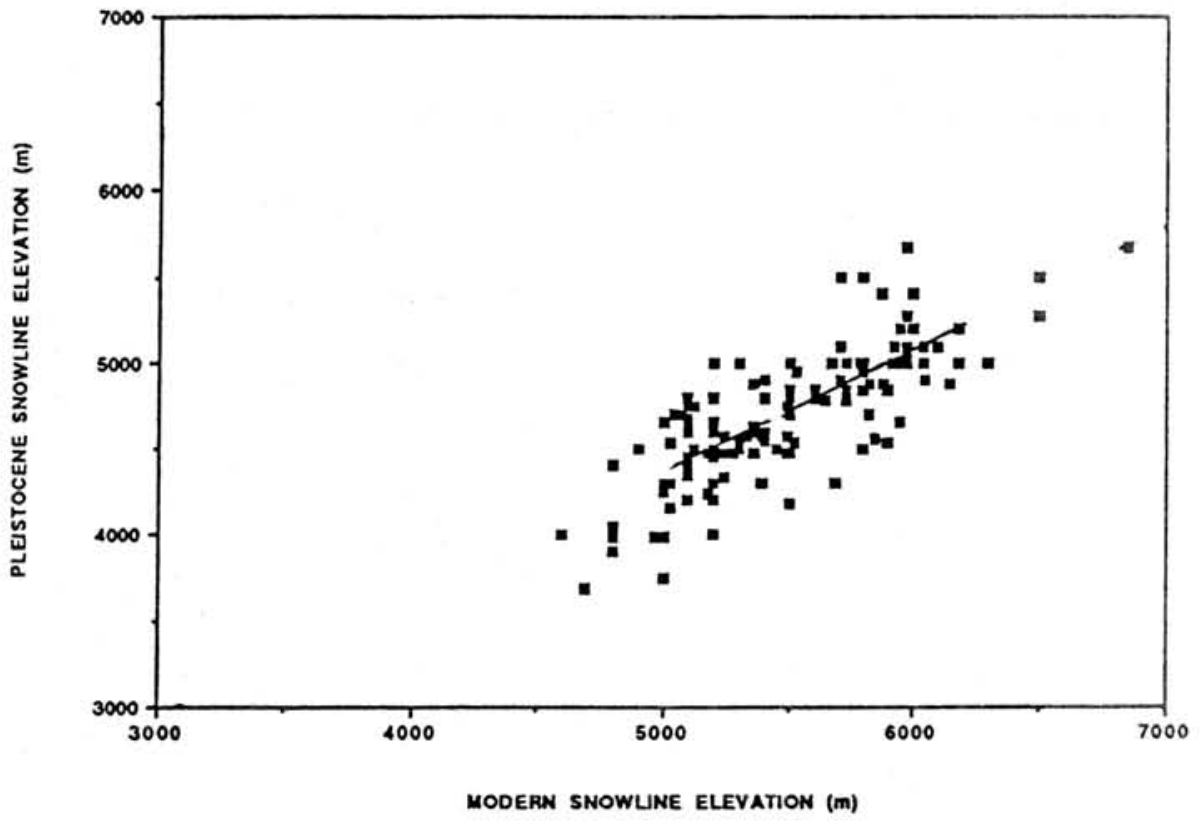

Figure 14 - Comparison of modern and late Pleistocene glacial-age snowline elevations in the central Andes (10-30 ${ }^{\circ} \mathrm{S}$ latitude).

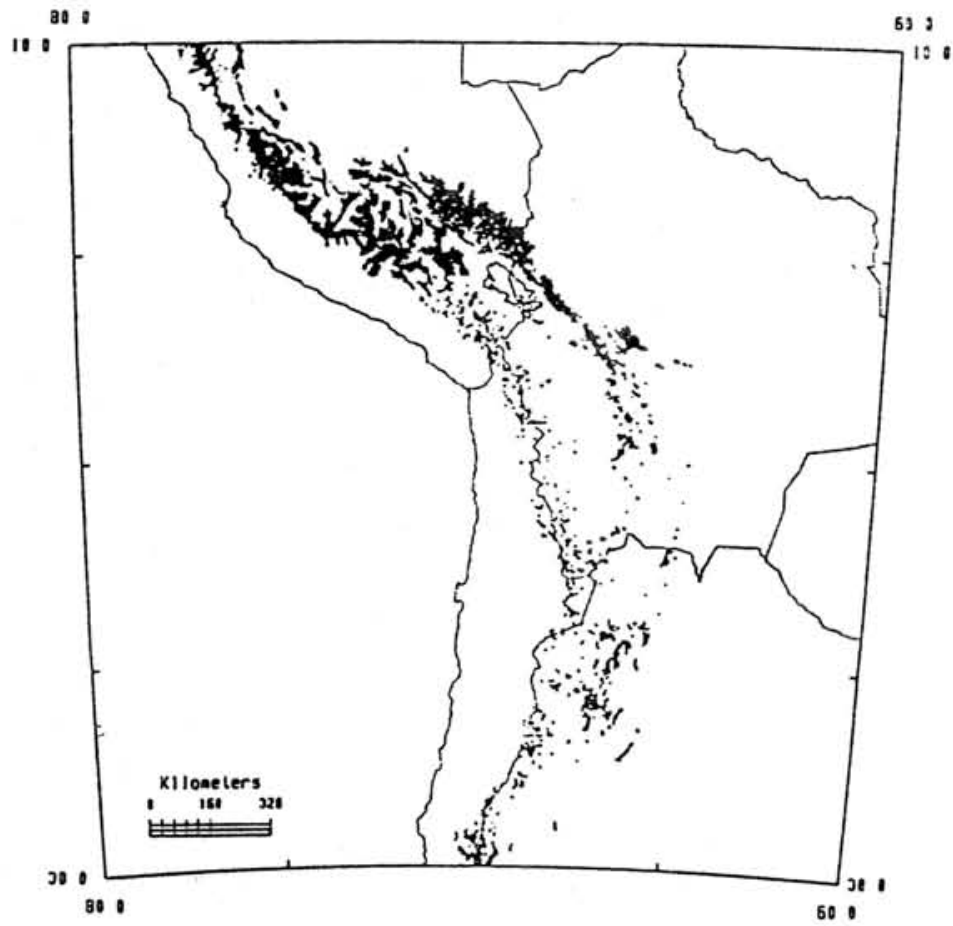

Figure 15 - Mapped extent of areas above late Pleistocene glacial-age snowline in the central Andes based on available data (NOGAMI, 1976 and STRECKER, 1987). The observed distribution of perennially snow-covered areas reflects the latitudinal variation in late Pleistocene climate and topography. Coordinates are in degrees south latitude and west longitude. 


\section{ACKNOWLEDGEMENTS}

Research for this paper was supported by NASA-JPL SIR-B continuation contract number 956926, Task Order RE-185 to Cornell University. I thank Professor Bryan Isacks for constructing the topo-climatic profiles and his assistance in refining the scope of this paper. Special thanks are also due Professor Arthur Bloom for his guidance during the development of the snowline model, and Chalmes Clapperton for editing the manuscript.

\section{REFERENCES}

HENNING, I. \& HENNING, D. (1981) Potential evapotranspiration in Mountain geoecosystems of different altitudes and latitudes. Mountain Research and Development, 1(3-4):267-274.

NOGAMI, M. (1976) Altitude of the modern and Pleistocene snowline in the Andes. Geographical Reports of Tokyo Metropolitan University, 11:71-86.

SCHWERDTFEGER, W. (1976) Climates of Central and South America Amsterdam, Elsevier. 532p. (World Survey of Climatology, 12).

STRECKER, M.R. (1987) Late Cenozoic landscape development the Santa Marina Valley, northwest Argentina. Ithaca, 261p. (Ph.D. Thesis - Cornell University). 